\section{A Global Health Elective Addresses Georgetown Resident Team and Cameroon Host Expectations: A Ten Year Comparative Analysis of Evaluation Surveys, 2004-2013}

\section{Marilee CS Cole, MD, DTMH*}

Office of the Executive Vice President (EVP), Georgetown University Medical Center, Washington, D. C., USA

\begin{abstract}
Objectives

The objectives were to assess strengths and weaknesses of the International Clinical Rotation (ICR) component, Georgetown Global Health Elective in Cameroon, 2004-2013, concomitantly, by Georgetown medicine resident team "guests" and Cameroon healthcare provider "hosts". Georgetown's ICR had 3 key elements: gradual clinical immersion, inpatient physician-pairing, and on-site American faculty supervision.

Method

A retrospective study was conducted using self-administered evaluation surveys by 26 Georgetown and 25 Cameroon survey participants, 2004-2013, who were asked if/how they would recommend changing 8 core components (variables) of Georgetown's ICR. Cameroon survey participants were asked further questions about "most positive" and "most negative" aspects, to uncover additional "host"-reported ICR strengths and weaknesses.

\section{Results}

The percentages of survey respondents in the Georgetown and in the Cameroon survey participant groups were not statistically significantly different $[50 \%(13 / 26)$ vs $52 \%(13 / 25), p=0.99, N S]$.

Of 8 variables, both survey respondent groups would not recommend changing 6 variables, including Academic content, Finances, On-call schedule, Professional relationship with other team's physicians, Special programs, and Work schedule.
\end{abstract}

*Corresponding author: Marilee CS Cole, MD, DTMH, Office of the Executive Vice President (EVP), Georgtown University Medical Center, Washington, D.C., USA, Tel: +17035327146; E-mail: marilee.cole@gmail.com

Citation: Cole MCS (2015) A Global Health Elective Addresses Georgetown Resident Team and Cameroon Host Expectations: A Ten Year Comparative Analysis of Evaluation Surveys, 2004-2013. J intern Med Prim Healthcare 1: 002.

Received: April 17, 2015; Accepted: May 19, 2015; Published: June 03, 2015

Georgetown and Cameroon survey respondents disagreed whether to recommend Academic format change, with significantly more Georgetown respondents recommending change [31\% $(4 / 13)$ vs $0 \%(0 / 13), p=0.0478, S]$. Thirty five percent $(35 \%)$ of Georgetown combined with Cameroon survey respondents agreed on recommending change to duration [35\% $(3 / 13+6 / 13=9 / 26)]$.

Cameroon survey respondents ranked Clinical teaching $[69 \%$ (9/13)], then Clinical care [38\% (5/13)], as two "most positive" aspects. Unexpectedly, Professional relationship with other team's physicians ranked third "most positive" aspect [23\% (3/13)]. Excess lab tests $[31 \%(4 / 13)]$, then "None" [23\% (3/13)], were two "most negative" aspects.

\title{
Conclusion
}

With strengths significantly outweighing weaknesses, Georgetown's international clinical rotation model elicited overall positive responses by Georgetown and Cameroon survey respondents. Further model optimization warrants systematic, prospective study of Academic format, Duration and Excess lab tests.

Keywords: Cameroon healthcare provider; Comparative analysis; Evaluation surveys; Global health elective; International clinical rotation; Internal medicine resident

\section{Abbreviations}

$\mathrm{BBH}$

CBCHS

GGHEC

GUMC

HIV/AIDS Acquired Immunodeficiency Syndrome

ICR

IRB

MGUH

NS

$\mathrm{S}$

\section{Introduction}

A challenge facing academic medicine is how to structure, implement and assess an ethically-sound, non-exploitive International Clinical Rotation (ICR), as part of a global health elective. This longitudinal study informs the quality of graduate medical education by presenting concomitant assessments of Georgetown's three-part clinical model by Georgetown internal medicine resident team "guests" and by their Cameroon healthcare provider "hosts".

\section{Background}

Internal medicine residents' interest in global health and international clinical experiences has increased [1-13]. Global health, animated by social justice aims to "improve health and achieve equity in health for all people worldwide" [14], resonates with physicians-in-training. Their residency directors anticipate more international clinical sites will be needed [6]. There are few detailed descriptions of the structure and function of residents' ICRs [3,15], 
and contrasting clinical rotation models [10,16]. Accordingly, there is a need to examine strengths and weaknesses evaluated by both healthcare provider "host" and "guest", concomitantly [17,18], to refine productive ICRs.

\section{The Georgetown International Clinical Rotation Model}

Medstar Georgetown University Hospital (MGUH) internal medicineresidents' interestin amedicalmission to Cameroon compelled the structuring of a safe and meaningful international clinical model. After review of other ICR models, we put forward the Georgetown clinical model with 3 key elements: gradual clinical immersion, inpatient physician-pairing and on-site American faculty supervision.

Gradual clinical immersion would foster the Georgetown internal medicine resident's provision of culturally-sensitive [18], cost-conscious medical care. Secondly, inpatient physician-pairing would facilitate mutual teaching of local competencies [19], by the Cameroon physician and by the Georgetown medicine resident. Lastly, on-site American faculty supervision addresses a resident's educational, safety, and supervisory concerns during the international clinical experience $[2,5,6,9,11,17,20$ 26]. On-site American faculty supervision would work to assure a safe clinical experience, as well as medical practice at the Georgetown resident's level of competence. This approach is responsive to the key component of inter-institutional arrangements for global health-the definition of a clearly structured educational program with appropriate supervision [19] and defined goals.

\section{Goals of Georgetown Global Health Elective in Cameroon}

1. Learn about global health

2. Teach global health as it relates to patient care

3. Provide clinical care to patients

4. Enhance medical infrastructure

\section{Setting}

Sub-Saharan Africa (SSA) has $13 \%$ of the world's population and $24 \%$ of the total burden of disease [27], but only $1.5 \%$ of the world's physicians [28]. These healthcare access disparities are even worse in remote SSA regions, making access to quality, affordable healthcare most difficult [29]. In remote Kumbo, Cameroon, West Africa, the 250 bed Banso Baptist Hospital (BBH) has a developing world clinical infrastructure. Cameroonian-run BBH incorporates "guest" medical trainees into preventative and curative healthcare services-once an on-site clinical supervisor is identified.

\section{Participant Selection Process}

Participants are Georgetown "guests" and Cameroon "hosts" who participated in the Georgetown Global Health Elective in Cameroon (GGHEC) international clinical rotation from 2004 and 2013 (Table 1). Georgetown participants, predominantly internal medicine residents, are selected early in internship for their senior year GGHEC program, following a 1 hour interview by the GGHEC Director. In contrast, Cameroon participants, predominantly practicing physicians, are selected by the GGHEC Director, in consultation with Cameroon Baptist Convention Health Services (CBCHS) leadership.

\begin{tabular}{|c|c|c|}
\hline & $\begin{array}{c}\text { Georgetown Group } \\
\text { (number, professional } \\
\text { category) }\end{array}$ & $\begin{array}{c}\text { Cameroon Group } \\
\text { (number, professional } \\
\text { category) }\end{array}$ \\
\hline \multirow[t]{5}{*}{ ICR Participants } & $\begin{array}{l}18 \text { Internal Medicine } \\
\text { Residents }\end{array}$ & 25 Physicians \\
\hline & $\begin{array}{l}4 \text { Medicine-Pediatrics } \\
\text { Residents }\end{array}$ & 5 Nurse/Nurse Practitioners \\
\hline & 2 Medical Students IV & 7 Healthcare Administrators \\
\hline & 5 Fellow or Faculty & \\
\hline & 1 GGHEC Director & \\
\hline \multirow[t]{3}{*}{$\begin{array}{l}\text { ICR Participant } \\
\text { Exclusions }\end{array}$} & $\begin{array}{l}2 \text { Medicine-Pediatrics } \\
\text { Residents }\end{array}$ & 4 Physicians \\
\hline & 1 Fellow or Faculty & 1 Nurse/Nurse Practitioners \\
\hline & 1 GGHEC Director & 7 Healthcare Administrators \\
\hline \multirow[t]{3}{*}{ Exclusion Reasons } & 3 Redundancy & 4 No E-mail Address \\
\hline & 1 Conflict of interest & $\begin{array}{l}1 \text { Family Medical Leave } \\
\text { (FML) }\end{array}$ \\
\hline & & 7 Non Healthcare Providers \\
\hline \multirow[t]{4}{*}{ Survey Participants } & $\begin{array}{l}18 \text { Internal Medicine } \\
\text { Residents }\end{array}$ & 21 Physicians \\
\hline & $\begin{array}{l}2 \text { Medicine-Pediatrics } \\
\text { Residents }\end{array}$ & 4 Nurse/Nurse Practitioners \\
\hline & 2 Medical Students IV & \\
\hline & 4 Fellow or Faculty & \\
\hline \multirow[t]{4}{*}{$\begin{array}{l}\text { Survey Respondents } \\
\text { \# (\% respondents/par- } \\
\text { ticipants) }\end{array}$} & $\begin{array}{c}9(50 \%) \text { Internal Medicine } \\
\text { Residents }\end{array}$ & 10 (48\%) Physicians \\
\hline & $\begin{array}{l}1(50 \%) \text { Med-Peds } \\
\text { Residents }\end{array}$ & $\begin{array}{c}3(75 \%) \text { Nurse/Nurse } \\
\text { Practitioners }\end{array}$ \\
\hline & $\begin{array}{c}1(50 \%) \text { Medical Students } \\
\text { IV }\end{array}$ & \\
\hline & $2(50 \%)$ Fellow or Faculty & \\
\hline
\end{tabular}

Table 1: Professional Composition of Georgetown and Cameroon International Clinical Rotation (ICR) Participants, Survey Participants, and Survey Respondents.

Georgetown Global Health Elective in Cameroon (GGHEC), 2004-2013 at Banso Baptist Hospital, Kumbo, Cameroon.

\section{Preparations}

During the 10 months prior to departure, Georgetown internal medicine resident team members and the GGHEC Director meet for 10-30 hours. Cameroon medical and cultural milieu is discussed. Georgetown residents are asked to identify their anticipated special contribution to $\mathrm{BBH}$ (Table 2). Georgetown residents submit 3 applications [CBCHS, Catholic Medical Mission Board (CMMB) for medical malpractice, travel and evacuation insurances, and US Visa], raise funds to cover travel costs and charitable donations, prepare a lecture, obtain immunizations, malaria prophylaxis, gloves/face masks, and study global health, including tropical diseases.

\section{The Experience}

After shadowing a Cameroon physician "host" for 1-3 days, the Georgetown internal medicine resident "guest" gradually begins to care for a small cohort of hospitalized BBH patients, in consultation with an on-site American faculty supervisor. Evaluating and treating these patients is challenging, given the prevalence of severe unfamiliar communicable diseases, limited laboratory and pharmacy, and plethora (270) of tribal languages and cultures. 
Afternoons are spent managing outpatients and attending American faculty-taught lecture/seminars on global health and the local implementation of evidence-based management of common diseases, such as HIV/AIDS, malaria and tuberculosis (Table 3). Rounding out the 6-day work week are BBH staff lectures and meetings, weekly mid-day Georgetown residents' lectures, and call every fourth night and weekend.

\begin{tabular}{|l|l|}
\hline Year & Special Contributions by Georgetown Team Members \\
\hline $\mathbf{2 0 0 4}$ & Surveyed Malaria Prophylaxis in Pregnancy \\
\hline $\mathbf{2 0 0 5}$ & Initiated Hematology and Pulmonary Consultancies \\
\hline $\mathbf{2 0 0 6}$ & $\begin{array}{l}\text { Co-wrote Opportunistic Infections Management Manual for the Cameroon } \\
\text { Baptist Convention Health Services (CBCHS) }\end{array}$ \\
\hline $\mathbf{2 0 0 7}$ & $\begin{array}{l}\text { Compiled Internal Medicine Curriculum for New Cameroon Internal Medicine } \\
\text { Residency Program at Mbingo Baptist Hospital }\end{array}$ \\
\hline $\mathbf{2 0 0 8}$ & Rewrote CBCHS Tuberculosis Training Manual Sections \\
\hline $\mathbf{2 0 0 9}$ & Initiated Medical Jeopardy Educational Game \\
\hline $\mathbf{2 0 1 0}$ & Ran Internal Medicine and Pediatrics Wards Solo for One Week \\
\hline $\mathbf{2 0 1 1}$ & Initiated Diabetes Mellitus, Gastroenterology, and Pediatrics Consultancies \\
\hline $\mathbf{2 0 1 2}$ & Established Tradition of Annual Fundraiser Events \\
\hline $\mathbf{2 0 1 3}$ & $\begin{array}{l}\text { Developed Medical Evacuation Protocol and Cervical Cancer Screening } \\
\text { Quality Improvement Project }\end{array}$ \\
\hline
\end{tabular}

Table 2: Special Contributions by Georgetown Team Members to Banso Baptist Hospital, Kumbo, Cameroon.

Georgetown Global Health Elective in Cameroon, 2004-2013.

\begin{tabular}{|c|l|}
\hline 1. & Global Health and Practicing Tropical Medicine in Cameroon \\
\hline 2. & Arrhythmias and Reading EKGs \\
\hline 3. & Management of Upper Gastrointestinal Bleeding \\
\hline 4. & Global Health and Medical Management of Commonly Lethal Diseases \\
\hline 5. & Overview of Diabetes Mellitus \\
\hline 6. & Gynecology Pearls \\
\hline 7. & HIV/AIDS Management \\
\hline 8. & HIV/AIDS and Cardiovascular Disease \\
\hline 9. & Introduction to Medical Emergencies \\
\hline 10. & Opportunistic Infections \\
\hline 11. & Indications for Medical Transfers \\
\hline 12. & Global Health and "TB or not TB" \\
\hline 13. & Management of the Unconscious Patient \\
\hline 14. & Global Health and Waging the War on Tropical Diseases \\
\hline 15. & Eosinophilia \\
\hline
\end{tabular}

Table 3: Sample Curriculum: Georgetown Global Health Elective in Cameroon Curriculum, 2013.

\section{Materials and Methods}

\section{Research questions}

The survey questionnaires (Supplementary files, Appendix I and Appendix II) were developed to assess the structural and functional adequacy of the Georgetown International Clinical Rotation (ICR) from the points-of-view of both Georgetown healthcare provider "guests" and Cameroon healthcare provider "hosts".

In this study, we addressed 2 questions:

1.Are strengths and weaknesses of "gradual clinical immersion, inpatient physician-pairing, on-site American faculty supervision" international clinical model comparable for Georgetown and Cameroon healthcare provider ICR participants?
2.Do qualitative questions asked of Cameroon participants uncover additional, unexpected Cameroon "host"-reported ICR strengths and weaknesses, not discovered through quantitative questions?

\section{Study population}

Two (2) study populations were identified. Study populations were derived from lists of Georgetown participants in the international clinical rotation component of Georgetown Global Health Electives in Cameroon, 2004-2013, and of their close Cameroon participant partners.

The Georgetown study group consisted, primarily, of former Georgetown internal medicine and medicine/pediatrics residents in graduation classes 2004-2013 [30], and, secondarily, of an occasional Georgetown medical student, fellow or faculty member, who acted as a healthcare provider and Georgetown team member.

The Cameroon study group consisted of healthcare provider partners, who were mostly Cameroon physicians, but also included an occasional nurse practitioner or nurse, who functioned equivalently to a Cameroon physician. Prior to exclusions, Cameroon healthcare administrators were also on the Cameroon study group list.

Lists of 30 Georgetown and of 37 Cameroon study group members were generated (Table 1). Four (4) Georgetown study group members were excluded, 3 for redundancy and 1 GGHEC Director for conflict of interest. Twelve (12) Cameroon study group members were excluded, 4 for no known e-mail address/es, 1 for family medical leave, and 7 healthcare administrators for not providing direct patient care.

Thus, 2 survey participant groups were identified, 26 Georgetown survey participants and 25 Cameroon survey participants. The Georgetown survey participants were significantly more white, American, female, physician trainees; the Cameroon survey participants were significantly more black, African, male, physician staff members (Supplementary file, Appendix III).

\section{Survey procedure}

Lists of Georgetown and Cameroon study group members were drawn from GGHEC records and correspondences, 2004-2013. Exclusions were applied and GGHEC ICR evaluation surveys (Supplementary files, Appendix I and Appendix II) were e-mailed to Georgetown and Cameroon survey participants, using their last known (within the last 10 years) personal e-mail addresses.

Active e-mail addresses were difficult to verify for both groups. At the time of the e-mailed survey, 88\% (23/26) of Georgetown survey participants had departed Medstar Georgetown University Hospital; $84 \%(21 / 25)$ of Cameroon survey participants, Banso Baptist Hospital.

Two (2) to 4 weeks after e-mailing the first survey, a second survey was e-mailed to non-responders, with no associated inducements or incentives.

The GGHEC Director collected and analyzed survey data from each survey respondent (Table 1). Confidentiality of responses was maintained.

\section{Survey instrument}

The survey was built with the Yale $[1,5,31]$ and Duke $[9,18]$ international health program studies in mind. However, in the Georgetown study, the survey participant cohort was expanded to include both Cameroon "host" and Georgetown "guest" healthcare providers, and narrowed to include one international site with the 
same American faculty supervisor for the majority $[90 \%(9 / 10)]$ of Georgetown team cohorts.

A core of 36 items was the same for both survey participant groups, including 16 "Recommendations for ICR Change" items and 20 work practice profile items. The remaining portions of the 2 questionnaires were group specific-with Georgetown survey participants asked additional questions about on-going and future plans for global health involvement; the Cameroon survey participants, about "most positive" and "most negative" ICR aspects, from the "host" viewpoint. In total, the Georgetown survey contained 55 items; the Cameroon survey, 70 items.

The information for this study came entirely from the survey instrument, except for some sociodemographic data which came from GGHEC ICR application records.

\section{"Variables"}

Eight (8) core determinants of structure and function of the GGHEC International Clinical Rotation (ICR) were deemed "variables". These 8 "variables" were derived from regular, on-going discussions about desired ICR characteristics with individuals from both Georgetown and Cameroon study groups, and were focused on meeting both groups' educational needs.

The 8 variables included:

1. Academic content

2. Academic format

3. Duration

4. Finances

5. On-call schedule

6. Professional relationship with other team's physicians

7. Special programs

8. Work schedule

In evaluation surveys, survey participants were asked "yes response" questions about need to change 8 "variables" or core ICR components, and were encouraged to explain if and how any "variables" should be changed. (See Table 4 for details about each "variable"). Additionally, each Cameroon survey participant was asked to name the "most positive" and "most negative" aspects of the GGHEC ICR, in order to uncover additional ICR strengths and weaknesses.

\section{Survey respondent population}

The percentages of survey respondents in the Georgetown and Cameroon survey participant groups were not statistically significantly different $[50 \%(13 / 26)$ vs $52 \%(13 / 25), p=0.99$, NS].

The survey respondent groups reflected the same statistically significant differences found between the survey participant groups, except for gender differences, which were no longer statistically significant [31\% (4/13) Georgetown male vs 69\% (9/13) Cameroon male, $\mathrm{p}=0.1152$, NS]. Thus, the Georgetown survey respondent group continued to be significantly more white $[92 \%(12 / 13)$ vs $23 \%(3 / 13)$, $\mathrm{p}=0.001, \mathrm{~S}]$, American [85\% (11/13) vs $23 \%(3 / 13), \mathrm{p}=0.0048, \mathrm{~S}]$, and physician trainee $[92 \%(12 / 13)$ vs $15 \%(2 / 13), \mathrm{p}=0.0001, \mathrm{~S}]$, than the Cameroon survey respondent group, which continued to be more black, African and physician staff member.

\begin{tabular}{|c|c|}
\hline "Variables" & Descriptive details about each "Variable" \\
\hline Academic content & $\begin{array}{l}\circ \text { Global, international and public health } \\
\circ \quad \text { Tropical and internal medicine, based on local } \\
\text { epidemiology } \\
\circ \quad \text { Cultural, religious, and financial practice--based } \\
\text { issues }\end{array}$ \\
\hline Academic format & $\begin{array}{l}\circ \text { Supervision and assessment by Georgetown faculty } \\
\circ \text { Give 1-3 medical lectures at } \mathrm{BBH} ; 1 \text {, on return to } \\
\text { Georgetown } \\
\circ \quad \text { Attend 3-7 educational meetings/week } \\
\circ \quad \text { Attend debriefing meeting on return to Georgetown }\end{array}$ \\
\hline Duration & - 3 to 4 weeks \\
\hline Finances & $\begin{array}{l}\text { Raise } \$ 14,000 \text { ( } \$ 7000-\$ 20,000) \text { for travel/room/board } \\
(85 \% \text { of charitable funds) } \\
\text { Raise } \$ 2,500(\$ 500-\$ 2,800) \text { for } \mathrm{BBH} \text { teaching, } \\
\text { clinical care, medical infrastructure development } \\
\text { (15\% of charitable funds) }\end{array}$ \\
\hline On-call schedule & $\begin{array}{l}\circ \quad \text { Every 4th night } \\
\circ \quad 1 \text { weekend }\end{array}$ \\
\hline $\begin{array}{l}\text { Professional } \\
\text { relationship with } \\
\text { other team's } \\
\text { physicians }\end{array}$ & $\begin{array}{l}\text { Shadow Cameroon physician during initial } 1-3 \text { days } \\
\text { Physician-pairing on the hospital wards for mutual } \\
\text { teaching }\end{array}$ \\
\hline Special programs & $\begin{array}{l}\text { Innovative educational programs, curriculum } \\
\text { development, consultancies, protocols, surveys, } \\
\text { and/or fundraisers }\end{array}$ \\
\hline Work Schedule & $\begin{array}{ll}\circ & \text { Hospital patients in AM, Monday-Saturday } \\
\circ & \text { Outpatient clinic in PM, Monday-Saturday }\end{array}$ \\
\hline
\end{tabular}

Table 4: International Clinical Rotation "Variables", List and Descriptive Details.

Georgetown Global Health Elective in Cameroon, 2004-2013 at Banso Baptist Hospital (BBH), Kumbo, Cameroon.

\section{Statistical methods}

Because of small sample size in this study, the two-sided Fisher's exact test was used to compare binary data between two groups. All p-values $<0.05$ were considered to be Statistically Significant (S).

\section{Legal, ethical issues}

Evaluation surveys from both Georgetown and Cameroon survey respondent groups were gathered and analyzed. After survey data analysis revealed generalizable information for small size, international clinical rotation models, the GGHEC Director submitted and, subsequently, received IRB approval from Georgetown University Medical Center for a retrospective study. Waiver of consent was approved, and compliance with ethical regulations, with guarantee of privacy of responses, ensured. No conflicts of interest or outside funding related to this project were reported.

\section{Results}

Are the strengths and weaknesses of this Georgetown international clinical model comparable for both Georgetown and Cameroon survey respondent groups?

Agreement by Georgetown and Cameroon survey respondent groups on whether or not to recommend change to 7 of 8 international clinical rotation "variables"

The percentages of "yes responses" for each "variable" were calculated for Georgetown survey respondents and for Cameroon survey respondents (Table 5). There were no statistically significant differences between Georgetown and Cameroon survey respondent groups on 7 of 8 international clinical rotation "variables". These 7 "variables" included Academic content, Duration, Finances, On-call schedule, Professional relationship with other team's physicians, Special programs, and Work schedule. 


\begin{tabular}{|c|c|c|c|}
\hline Components ("Variables") of International Clinical Rotation & $\begin{array}{c}\text { Georgetown } \\
\text { "Yes" Response Rate } \\
\text { (\%, "yes"/total responses) }\end{array}$ & $\begin{array}{c}\text { Cameroon } \\
\text { "Yes" Response Rate } \\
\text { (\%, "yes"/total responses) }\end{array}$ & $p$ value, $\mathbf{S}$ \\
\hline Academic content & $8 \%(1 / 13)$ & $0 \%(0 / 13)$ & $\mathrm{P}=0.99, \mathrm{NS}$ \\
\hline Academic format & $31 \%(4 / 13)$ & $0 \%(0 / 13)$ & $P=0.0478, S$ \\
\hline Duration & $23 \%(3 / 13)$ & $46 \%(6 / 13)$ & $\mathrm{P}=0.25, \mathrm{NS}$ \\
\hline Finances & $15 \%(2 / 13)$ & $15 \%(2 / 13)$ & $\mathrm{P}=0.99, \mathrm{NS}$ \\
\hline Professional relationship with other team's physicians & $8 \%(1 / 13)$ & $15 \%(2 / 13)$ & $P=0.99, N S$ \\
\hline Special programs & $0 \%(0 / 13)$ & $15 \%(2 / 13)$ & $\mathrm{P}=0.48, \mathrm{NS}$ \\
\hline Work schedule & $8 \%(1 / 13)$ & $0 \%(0 / 13)$ & $\mathrm{P}=0.99, \mathrm{NS}$ \\
\hline
\end{tabular}

Table 5: Comparison between Georgetown and Cameroon Survey Respondents in Their Recommendations for Change of the International Clinical Rotation.

Georgetown Global Health Elective in Cameroon, 2004-2013.

However, the Georgetown and Cameroon survey respondent groups significantly differed in their assessment of Academic format. Although almost one third of Georgetown survey respondents would change Academic format, no Cameroon survey respondents would do so $[31 \%(4 / 13)$ vs $0 \%(0 / 13), p=0.0478, S]$. In the aggregate, the Georgetown survey respondents would add back various components of a traditional American academic internal medicine residency rotation, such as a preparatory course, more case-based discussions, more resident lectures, and a small research project (Supplementary file, Appendix IV). However, no specific Georgetown Academic format "change recommendation" differed significantly from the Cameroon "no change recommendation" [15\% (2/13) vs 0\% (0/13), $\mathrm{p}=0.48$, Not Significant (NS)]. Academic format, although a mild weakness for the Georgetown survey respondents, was unanimously a strength for the Cameroon survey respondents.

In summary, Georgetown and Cameroon survey respondents agreed on a majority of the strengths and weaknesses of the Georgetown international clinical rotation model.

Do qualitative questions uncover unexpected Cameroon "host"-reported ICR strengths and weaknesses not discovered through the quantitative questions?

Qualitative responses by the Cameroon survey respondents about the "most positive" and "most negative" ICR aspects were grouped and categorized by themes, then percentages calculated in order to identify additional, "host"-reported ICR strengths and weaknesses (Table 6). When the Cameroon survey respondents were asked to name the "most positive" aspect, nearly half [46\% (6/13)] of Cameroon survey respondents named two "most positive" aspects; each topic was counted. Clinical teaching [69\% (9/13)], followed by Clinical care $[38 \%(5 / 13)]$, were ranked first and second "most positive" aspects. Unexpectedly, Professional relationship with other team's physicians $[23 \%(3 / 13)]$ ranked third.

When the Cameroon survey respondents were asked to identify the "most negative" aspect, Excess lab tests [31\% (4/13)] ranked at the top, followed, unexpectedly, by "None" [23\% (3/13)]. Limited stay and Cultural adjustment [15\% (2/13)] tied for third "most negative" aspect. Thus, qualitative questions asked of the Cameroon "hosts" uncovered both unexpected strengths and unexpected weaknesses of Georgetown's international clinical model.

\section{Discussion}

The evaluation survey assessment of Georgetown and Cameroon survey responses shows broad agreement on the strengths and

\begin{tabular}{|l|c|}
\hline \multicolumn{1}{|c|}{$\begin{array}{c}\text { Qualitative Answers } \\
\text { by Cameroon Survey Respondents }\end{array}$} & $\begin{array}{c}\text { Quantity of Responses } \\
\text { (\# respondents to name topic) } \\
\text { total \# survey respondents }\end{array}$ \\
\hline Most positive aspect of elective & $69 \%(9 / 13)$ \\
\hline Clinical teaching & $38 \%(5 / 13)$ \\
\hline Clinical care & $23 \%(3 / 13)$ \\
\hline $\begin{array}{l}\text { Professional relationship with other } \\
\text { team's physicians }\end{array}$ & $8 \%(1 / 13)$ \\
\hline Religious and Cultural involvement & $8 \%(1 / 13)$ \\
\hline Medical supplies & \\
\hline Most negative aspect of elective & $31 \%(4 / 13)$ \\
\hline Excess lab tests & $23 \%(3 / 13)$ \\
\hline None & $15 \%(2 / 13)$ \\
\hline Cultural adjustments & $15 \%(2 / 13)$ \\
\hline Limited stay & $8 \%(1 / 13)$ \\
\hline Limited patient management solutions & $8 \%(1 / 13)$ \\
\hline Limited long term physician relationship & $100 \% 13 / 13$ \\
\hline Was elective a net benefit? & \\
\hline
\end{tabular}

Table 6: Qualitative Answers by Cameroon Survey Respondents on "Most Positive" and "Most Negative" Aspects of the International Clinical Rotation.

Georgetown Global Health Elective in Cameroon, 2004-2013 at Banso Baptist Hospital, Kumbo, Cameroon.

weaknesses of the International Clinical Rotation component of GGHEC, 2004-2013. The disagreements between the Georgetown and Cameroon survey respondent groups are few, suggesting that the tripartite international clinical model, defined by gradual clinical immersion, inpatient physician-pairing and on-site American faculty supervision, has found a balance for an international clinical rotation.

\section{Advanced planning and agreement on strengths of 6 "variables"}

Specifically, both Georgetown and Cameroon survey respondent groups agree that Academic content, Finances, On-call schedule, Professional relationship with other team's physicians, Special programs, and Work schedule should remain unchanged, and are net strengths. These positive findings are not unexpected, since these 6 "variables" evolved into the present ICR formulation through 4 years of close, on-site consultation with Cameroon healthcare provider "hosts" by the future GGHEC Director, prior to GGHEC's 2004 initiation.

Much of the Academic content in lectures and handouts is an outgrowth of discussions between Georgetown and Cameroon ICR 
participants on optimum, evidence-based management of common Cameroon diseases impacted by global health issues; it significantly contributes to fulfilling Goal \#1 Learn about Global Health. Professional relationship with other team's physicians is facilitated by inpatient physician-pairing. Special programs are products of clinical challenges faced by both groups, and significantly contribute to fulfilling Goal \#4 Enhance Medical Infrastructure. Work-week and night/weekend call frequency are standard for the Cameroon hospital, BBH. Finances are discussed with Georgetown ICR participants, most of whom raised funds to cover trip and charitable expenses, and with CBCHS leadership, but less so with Cameroon ICR participants. Consequent to 4 years of planning, 6 of the 8 "variables" evolved as strengths for both Georgetown and Cameroon ICR participant groups.

\section{Change the duration "variable"}

Duration is a mild weakness for both Georgetown and Cameroon survey respondent groups. Even with on-site American faculty supervisory assistance, the Cameroon ICR participants still expend a substantial effort during the first 2 ICR weeks to educate the Georgetown ICR participants to function medically. By the third week, Georgetown ICR participants are functioning medically, only to depart the following week. Lengthening duration could eliminate duration as a mild weakness for both groups, but especially for the overworked Cameroon ICR participant "hosts".

\section{Adjust to an unfamiliar academic format or change it?}

Strength with respect to the Academic format "variable" is different among the groups. Whereas Cameroon survey respondents unanimously agree that Academic format should remain unchanged and is strength for them, a significantly smaller fraction [69\% (9/13)] of Georgetown survey respondents would agree. The Academic format, which superimposes a Georgetown supervisory format on a somewhat more informal Cameroon consultative format, is familiar to Cameroon healthcare provider "hosts", who regularly host visiting American physicians at their hospital, BBH. For Georgetown internal medicine resident "guests", this unfamiliar blend of teaching and practice methods requires on-going medical acculturation. Further questioning of both Georgetown and Cameroon groups may identify an optimum Academic format change to consider; pre-intervention and post-intervention assessments could determine the change's acceptability to both "guest" and "host" groups.

\section{Qualitative questions uncover unexpected, additional,} Cameroon "host"-reported ICR strengths and weaknesses

Of the 3 Georgetown Global Health Elective in Cameroon Goals directed towards supporting Cameroon "hosts", Cameroon survey respondents rank Goal \#2 Teach Global Health, then Goal \#3 Provide Clinical Care, as the first, then second, "most positive" ICR aspects. Unexpectedly, Professional relationship with other team's physicians is cited as the third "most positive" aspect. Further study as to what aspects of Professional relationship with other team's physicians are most important and meaningful to Cameroon "hosts" is warranted.

Cameroon survey respondents identify Excess lab tests as the most "negative" ICR aspect. A worrisome critique for resource-poor $\mathrm{BBH}$, the Excess lab tests critique warrants further investigation to determine if/how/by whom that Excess lab tests are ordered. An analysis oflab testexpendituresbyGeorgetown, compared toCameroon, ICR participants on a few common Cameroon diseases, controlling for disease severity, is indicated. Results from such a study couldhelptofocuson-goingeducationaleffortstolimitExcesslabtestsand elucidate areas for future fiscal restraint.

In summary, qualitative questions did uncover unexpected, Cameroon "host"-reported ICR strengths, as well as weaknesses.

\section{Limitations}

Interpretation of these research findings is limited by the non-anonymous nature of the retrospective evaluation survey, small individual cohort sizes, and the multiplicity of factors. The 51\% average response rate may be subject to bias in that respondents may assess the Georgetown Global Health Elective in Cameroon ICR more positively than their non-respondents. The small cohort sizes of both Georgetown and Cameroon ICR participant groups, render significant differences limited to the largest response differences among groups. Lastly, although tempting to attribute the survey's overall positive assessment to the tripartite international clinical rotation model, other factors, including the high caliber of Georgetown [30] and Cameroon ICR participants and leaders, consistency and continuity in leadership, as well as strong Cameroon institutional support, may equally contribute to Georgetown's tripartite international clinical rotation model's success.

\section{Conclusion}

The 10 year experience of Georgetown's international clinical model elicited comparable and overall positive quantitative responses by both Georgetown medicine resident team and Cameroon healthcare provider survey respondents.

Qualitative questions asked only of Cameroon "hosts" did uncover unexpected additional strengths, such as Professional relationship with other team's physicians, as well as weaknesses, such as Excess lab tests. Overall, though, the model's strengths significantly outweighed its weaknesses and fulfilled the four GGHEC goals.

The 3 key elements of this model are gradual clinical immersion, inpatient physician-pairing, and on-site American faculty supervision. To further optimize this tripartite model, weaknesses, such as Excess lab tests, Academic format, and Duration, as well as strengths, such as Clinical teaching, Clinical care and Professional relationships with other team's physicians, warrant additional study. A systematic prospective study of Georgetown's international clinical model could assist in further optimizing the model's strengths and minimizing its weaknesses.

\section{Acknowledgements}

The author gratefully thanks GU Health Services Executive Vice President Howard Federoff, MD, PhD, CBCHS Director of Health Services Pius Tih, JD, PhD, MPH, Catholic Medical Mission Board, Georgetown Women in Medicine, GUMC Professor of Medicine Joseph Verbalis, MD, GUMC Biostatisticians Jiji Jiang, MD, MS, and Associate Professor of Biostatistics Hongbin Fang, PhD for their excellent support.

\section{References}

1. Barry M, Bia FJ (1986) Departments of medicine and International health. Am J Med 80: 1019-1021.

2. Drain P, Holmes K, Skeff K, Hall TL, Gardner P (2009) Global health training and international clinical rotations during residency: current status, needs, and opportunities. Acad Med 84: 320-325. 
3. Einterz RM, Kelley CR, Mamlin JJ, Van Reken DE (1995) Partnerships in international health: the Indiana University-Moi University experience. Infect Dis Clin North Am 9: 453-455.

4. Furin J, Farmer P, Wolf M, Levy B, Judd A, et al. (2006) A novel training model to address health problems in poor and underserved populations. $J$ Health Care Poor Underserved 17: 17-24.

5. Gupta AR, Wells CK, Horwitz RI, Bia FJ, Barry M (1999) The Internationa Health Program: the fifteen-year experience with Yale University's internal medicine residency Program. Am J Trop Med Hyg 61: 1019-1023.

6. Kolars J, Halvorsen A, McDonald F (2011) Internal medicine residency directors perspectives on global health experiences. Am J Med 124: 881-885.

7. Macfarlane SB, Agabian N, Novotny TE, Rutherford GW, Stewart CC, et al (2008) Think globally, act locally, and collaborate internationally: global health sciences at the university of California, San Francisco. Acad Med 83: 173179.

8. McKinley DW, Williams SR, Norcini JJ, Anderson MB (2008) International exchange programs and US medical schools. Acad Med 83: 53-57.

9. Miller WC, Corey GR, Lallinger GJ, Durack DT (1995) International health and internal medicine residency training: the Duke University experience. Am J Med 99: 291-297.

10. Ravdin JI, Peterson PK, Wing E, Ibrahim T, Sande MA (2006) Globalization: a new dimension for academic internal medicine. Am J Med 119: 805-810.

11. Sawatsky A, Rosenman D, Merry S, McDonald FS (2010) Eight years of the Mayo International Health Program: what an international elective adds to resident education. Mayo Clin Proc 85: 734-741.

12. Thompson MJ, Huntington MK, Hunt DD, Pinsky LE, Brodie JJ (2003) Educational effects of international health electives on US and Canadian medica students and residents: a literature review. Acad Med 78: 342-347.

13. Velji A (2011) Global Health Education Consortium: 20 years of leadership in global health and global health education. Infect Dis Clin North Am 25 323-335.

14. Koplan JP, Bond TC, Merson MH, Reddy KS, Rodriguez MH, et al. (2009) Towards a common definition of global health. Lancet 373: 1993-1995.

15. Federico SG, Zachar PA, Oravec CM, Mandler T, Goldson E, et al. (2006) A successful international child health elective, the University of Colorado, Department of Pediatrics' experience. Arch Pediatr Adolesc Med 160: 191-196.

16. Rassiwala J, Vaduganathan M, Kupershtok M, Castillo FM, Evert J (2013) Global health educational engagement-a tale of two models. Acad Med 88: 1651-1657.

17. Crump J, Sugarman J, Working Group on Ethics Guidelines for Global Health Training (WEIGHT) (2010) Ethics and best practices guidelines for training experiences in global health. Am J Trop Med Hyg 83: 1178-1182.

18. Kraeker C, Chandler C (2013) "We learn from them, they learn from us": global health experiences and host perceptions of visiting health care professionals. Acad Med 88: 483-487.

19. Peluso MJ, Encandela J, Hafler JP, Margolis CZ (2013) Guiding principles for the development of global health education curricula in undergraduate medical education. Med Teach 34: 653-658.

20. Crump J, Sugarman J (2008) Ethical considerations for short-term experiences by trainees in global health. JAMA 300: 1456-1458.

21. Dandu M (2011) Trainee safety in global health. J Gen Intern Med 26: 826827

22. Drain PK, Primack A, Hunt DD, Fawzi WW, Holmes KK, et al. (2007) Global health in medical education: a call for more training and opportunities. Acad Med 82: 226-230.

23. Evert J, Bazemore A, Hixon A, Withy K (2007) Going global: considerations for introducing global health into family medicine training programs. Fam Med 39: $659-665$
24. Gardner A, Cohen T, Carter E (2011) Tuberculosis among participants in an academic global health medical exchange program. J Gen Intern Med 26: 841-845.

25. Kolars JC, Cahill K, Donkor P, Kaaya E, Lawson A (2012) Perspective: partnering for medical education in Sub-Saharan Africa: seeking the evidence for effective collaborations. Acad Med 87: 216-220.

26. Schultz S, Rousseau S (1998) International health training in family practice residency programs. Fam Med 30: 29-33.

27. WHO (2000) Disease burden, by region, DALY estimates, 2000-2012, global summary estimates. Health statistics and information systems.

28. Mullan F, Frehywot S, Chen C, Greysen R, Wassermann T, et al (2010) The Sub-Saharan African Medical Schools Study: Data, observation, and opportunity, report brief.

29. Sekhri N (2006) From Funding to Action: Strengthening healthcare systems in Sub Saharan Africa. World economic forum white paper, centre for public-private partnership, Global health initiative.

30. [Data not shown] A statistically significantly higher percentage of Georgetown internal medicine resident survey participants became Georgetown chief medicine residents compared to their non-Cameroon-bound classmates $[50 \%(10 / 20)$ vs. $22 \%(64 / 290), p<0.02$, Significant]. Additionally, seventy seven percent $(77 \%)$ of Georgetown graduates were either academic faculty or academic trainees at the time of the survey.

31. Barry M (1990) International health and general internal medicine. J Gen Intern Med 5: 454-455.

\section{Supplementary File}

\section{Appendix I}

\section{Evaluation Surveys for Georgetown International Clinical Rotation Participants}

Georgetown Global Health Elective in Cameroon, 2004-2013

\section{Involvement in Global Health}

1. Yes [ ] No [ ] Have you remained involved in global health after working in Cameroon through the Georgetown Global Health Elective?

If yes, you have remained involved in global health:

a. Yes [ ] No [ ] have you remained involved through caring for immigrant patients or international travelers in your US-based practice?

b. Yes [ ] No [ ] have you participated in other international medical missions since Cameroon?

c. Yes [ ] No [ ] have you remained involved through charitable giving?

Comments:

\section{Involvement in Georgetown Global Health Elective in Cameroon}

2. Yes [ ] No [ ] Are you interested in becoming involved in the Georgetown Global Health Elective in Cameroon?

If yes, are you interested in performing any of the following functions/jobs:
a. Yes [ ] No [ ] On-Site Team Leader?
b. Yes [ ] No [ ] On-site Consultant? 

c. Yes [ ] No [ ] US-based e-Consultant?
d. Yes [ ] No [ ] US-based Coordinator?
e. Yes [ ] No [ ] Fundraiser?
f. Yes [ ] No [ ] Charitable Donor?
g. Yes [ ] No [ ] Other?

3. If you are interested in involvement, when would you be available?

4. Yes [ ] No [ ] If you are interested in on-site involvement, and assuming \$3000 in on-site expenses, do you require financial support?

Comments:

\section{Recommendations for Changes to the Georgetown Global Health Elective in Cameroon}

5. Would you alter or change the following aspects of the Georgetown Global Health Elective in Cameroon?
a. Yes [ ] No [ ] Duration
b. Yes [ ] No [ ] Work Schedule
c. Yes [ ] No [ ] On-Call Schedule
d. Yes [ ] No [ ] Academic Format
e. Yes [ ] No [ ] Academic Content
f. Yes [ ] No [ ] Professional Relationship with Other Team's Physicians
g. Yes [ ] No [ ] Finances
h. Yes [ ] No [ ] Special Programs

Please comment on how you would make those recommended changes:

\section{Your Present Work Setting}

6. In what setting do you presently work? Check all that apply.
a. Private [ ], Public [ ], Academic (trainee) [ ], Academic (faculty) [ ], other [ ]
b. Hospital [ ], Outpatient Clinic [ ], Other [ ]
c. Rural [ ], Suburban [ ], Urban [ ]

7. Are you working in the following field/s of medicine presently?
a. Yes [ ] No [ ] General Internal Medicine
b. Yes [ ] No [ ] Subspecialty Medicine
c. Yes [ ] No [ ] Public Health
d. Yes [ ] No [ ] Other

8. Are you involved in the following professional activities presently?
a. Yes [ ] No [ ] Clinical practice
b. Yes [ ] No [ ] Medical Education
c. Yes [ ] No [ ] Research

d. Yes [ ] No [ ] Administration

e. Yes [ ] No [ ] Other

Comments:

\section{Optional Information}

9. Home number Cell phone

10. Present job description

11. Present work address

12. Future work plans

Thank you for completing this survey!

\section{Supplementary File}

\section{Appendix II}

\section{Evaluation Surveys for Cameroon International Clinical Rotation} Partners

Georgetown Global Health Elective in Cameroon, 2004--2013

\section{Evaluation of and Recommendations for Change to the Elective}

1. Would you alter or change the following aspects of the Elective?

a. Yes [ ] No [ ] Preparation

b. Yes [ ] No [ ] Duration

c. Yes [ ] No [ ] Work Schedule

d. Yes [ ] No [ ] On-Call Schedule

e. Yes [ ] No [ ] Academic Format

f. Yes [ ] No [ ] Academic Content

g. Yes [ ] No [ ] Professional Relationship with Other Team's Physicians

h. Yes [ ] No [ ] Special Programs

i. Yes [ ] No [ ] Charitable Donations

j. Yes [ ] No [ ] Finances

k. Yes [ ] No [ ] Religious/Cultural

2. How would you alter or change the following aspects of the Elective?
a. Preparation
b. Duration
c. Work Schedule
d. On-Call Schedule
e. Academic Format
f. Academic Content
g. Professional Relationship with Other Team's Physicians
h. Special Programs
i. Charitable Donations 
j. Finances

k. Religious/Cultural

Comments:

3. What is the most positive aspect of the Elective?

4. What is the most negative aspect of the Elective?

5. Yes [ ] No [ ] Is the Elective a net benefit to the CBCHS?

If so, how?

6. In what capacity have you worked with the Georgetown participants in the Georgetown Global Health Elective in Cameroon between 2004-2013?

a. Yes [ ] No [ ] Teacher

b. Yes [ ] No [ ] Supervisor

c. Yes [ ] No [ ] Mentor

d. Yes [ ] No [ ] Inpatient Team Member

e. Yes [ ] No [ ] Outpatient Team Member

f. Yes [ ] No [ ] Student

g. Yes [ ] No [ ] Administrator

h. Yes [ ] No [ ] Subordinate

i. Yes [ ] No [ ] Other

Comments:

\section{Your Present Work Setting}

7. In what setting do you presently work? Check all that apply.

a. Group Practice [ ] Private Practice [ ] Academic (faculty) [ ], Other [

b. Hospital [ ], Outpatient Clinic [ ], Other [ ]

c. Rural [ ], Suburban [ ], Urban [ ]

d. In Cameroon [ ], In Another Country [ ] which one/s?
8. In what field/s of medicine are you presently working? Check all that apply.
a. Yes [ ] No [ ] Internal Medicine
b. Yes [ ] No [ ] Subspecialty Medicine
c. Yes [ ] No [ ] Public Health
d. Yes [ ] No [ ] Other

9. In which of the following professional activities are you presently involved?

Check all that apply.

a. Yes [ ] No [ ] Clinical Practice

b. Yes [ ] No [ ] Medical Education

c. Yes [ ] No [ ] Research

d. Yes [ ] No [ ] Administration

e. Yes [ ] No [ ] Other

Comments:

\section{CBCHS Leadership Role/s}

10. Yes [ ] No [ ] Do you have a leadership role in the CBCHS?

Describe your leadership role:

\section{Optional Information}

11. Present job description

12. Future work plans

13. Educational Degrees [ ] MD, [ ] PhD, [ ] Other doctorate [ ] MPH, [ ] MBA, [ ] Other masters_, [ ] RN, [ ] Bachelors , [ ] LPN, [ ] Other Degree/s

Thank you for completing this survey! 
Citation: Cole MCS (2015) A Global Health Elective Addresses Georgetown Resident Team and Cameroon Host Expectations: A Ten Year Comparative Analysis of Evaluation Surveys, 2004-2013. J intern Med Prim Healthcare 1: 002.

\section{Supplementary File}

\section{Appendix III}

Comparison of Sociodemographic Characteristics between Georgetown and Cameroon Survey Participant Groups, then between Survey Respondent Groups

Georgetown Global Health Electives in Cameroon (GGHEC), 2004-2013

\begin{tabular}{|c|c|c|c|c|c|c|}
\hline & $\begin{array}{l}\text { Georgetown Survey } \\
\text { Participants }\end{array}$ & $\begin{array}{c}\text { Cameroon } \\
\text { Survey Participants }\end{array}$ & $p$-value, $\mathbf{S}$ & $\begin{array}{l}\text { Georgetown Survey } \\
\text { Respondents }\end{array}$ & $\begin{array}{l}\text { Cameroon Survey } \\
\text { Respondents }\end{array}$ & p-value, $\mathbf{s}$ \\
\hline $\begin{array}{l}\text { Gender } \\
\text { Male } \\
\text { Female }\end{array}$ & $\begin{array}{c}9(35 \%) \\
17(65 \%)\end{array}$ & $\begin{array}{l}18(72 \%) \\
7(28 \%)\end{array}$ & $0.0115, \mathrm{~s}$ & $\begin{array}{l}4(31 \%) \\
9(69 \%)\end{array}$ & $\begin{array}{l}9(69 \%) \\
4(31 \%)\end{array}$ & $0.1152, \mathrm{NS}$ \\
\hline $\begin{array}{l}\text { Race } \\
\text { Caucasian } \\
\text { African/ Asian }\end{array}$ & $\begin{array}{c}23(88 \%) \\
3(12 \%)\end{array}$ & $\begin{array}{c}5(20 \%) \\
20(80 \%)\end{array}$ & $<0.0001, \mathrm{~S}$ & $\begin{array}{c}12(92 \%) \\
1 \quad(8 \%)\end{array}$ & $\begin{array}{c}3(23 \%) \\
10(77 \%)\end{array}$ & $0.001, \mathrm{~s}$ \\
\hline $\begin{array}{l}\text { Occupation } \\
\text { Trainee } \\
\text { Faculty/Staff }\end{array}$ & $\begin{array}{c}23(88 \%) \\
3(12 \%)\end{array}$ & $\begin{array}{c}5(20 \%) \\
20(80 \%)\end{array}$ & $<0.0001, \mathrm{~S}$ & $\begin{array}{l}12(92 \%) \\
1 \quad(8 \%)\end{array}$ & $\begin{array}{l}2(15 \%) \\
11(85 \%)\end{array}$ & $0.0001, \mathrm{~s}$ \\
\hline $\begin{array}{l}\text { Physician } \\
\text { Non-Physician }\end{array}$ & $\begin{array}{c}26(100 \%) \\
0 \quad(0 \%)\end{array}$ & $\begin{array}{c}21(84 \%) \\
4(16 \%)\end{array}$ & 0.051 , NS & $\begin{array}{c}13(100 \%) \\
0(0 \%)\end{array}$ & $\begin{array}{c}10(77 \%) \\
3(23 \%)\end{array}$ & 0.11 , NS \\
\hline
\end{tabular}

\section{Supplementary File}

\section{Appendix IV}

Description of Georgetown Survey Respondents' Recommendations for Change of International Clinical Rotation "Variables"

Georgetown Global Health Electives in Cameroon (GGHEC), 2004-2013

\begin{tabular}{|c|c|c|}
\hline International Clinical Rotation "Variables" & $\begin{array}{c}\text { Description of } \\
\text { Recommended Change }(\Delta)\end{array}$ & $\begin{array}{l}\%(\# \text { times } \Delta \text { listed }) \\
\text { (\# total participants) }\end{array}$ \\
\hline Academic Content & & $0 \%(0 / 13)$ \\
\hline Academic Format & $\begin{array}{l}\text { a. Tropical medicine course prior to departure } \\
\text { b. More resident lectures } \\
\text { c. More case-based discussions } \\
\text { d. Add small research project }\end{array}$ & $\begin{array}{l}\text { a. } 8 \%(1 / 13) \\
\text { b. } 8 \%(1 / 13) \\
\text { c. } 8 \%(1 / 13) \\
\text { d. } 15 \%(2 / 13)\end{array}$ \\
\hline Duration & Increase duration of trip & $15 \%(2 / 13)$ \\
\hline Finances & More financial support & $8 \%(1 / 13)$ \\
\hline \multicolumn{3}{|l|}{ On-call Schedule } \\
\hline $\begin{array}{l}\text { Professional Relationship with Other } \\
\text { Team's Physicians }\end{array}$ & $\begin{array}{l}\text { Residents function as consultant attendings; medical students, } \\
\text { as Cameroon physician team members }\end{array}$ & $8 \%(1 / 13)$ \\
\hline Special Programs & & $0 \%(0 / 13)$ \\
\hline Work Schedule & & $0 \%(0 / 13)$ \\
\hline
\end{tabular}

